\title{
The effects of obesity with pregnancy termination: a literature review
}

\author{
Katherine E. Roberts, BA, ${ }^{1}$ Abbey J. Hardy-Fairbanks, MD, ${ }^{2}$ \\ Colleen K. Stockdale, MD, MS $^{2}$
}

Keywords: Obesity, body mass index, pregnancy termination, abortion, first trimester abortion, second trimester abortion

\begin{abstract}
Obesity has become a major health problem in the United States as well as globally which may affect the safety of pregnancy termination. Thus, a literature review was conducted to determine the available evidence regarding the effects of obesity with pregnancy termination to assist with patient care and counseling. The available evidence is limited by small numbers and descriptive study design. While pregnancy termination upon obese women may impart additional technical challenges, experienced providers complete procedures upon obese women without statistically significant differences in procedure or patient outcomes compared to normal weight women for first trimester gestations. Pharmacological abortion may be a more practical option in some very obese women.

${ }^{1}$ University of lowa Carver College of Medicine, lowa City, lowa

${ }^{2}$ University of lowa Hospitals and Clinics, Department of Obstetrics and Gynecology, lowa City, lowa
\end{abstract}

\section{Background}

Obesity has become a major global health problem and is dramatically increasing in the United States. The Center for Disease Control and Prevention estimates that over $42 \%$ of the United States population is obese, and projects that by 2030 all 50 states will have an obesity rate of $44 \%$ or greater, which could represent a $\$ 550$ billion increase in obesity related national costs. ${ }^{1}$ Obesity is associated with a number of pregnancy related complications for both mother and fetus. Risks for the mother include gestational diabetes, hypertension, preeclampsia, postpartum hemorrhage, cesarean delivery, and wound infection. ${ }^{2}$ Risks for the fetus include prematurity, stillbirth, congenital anomalies, macrosomia with possible birth injury, and childhood obesity. $^{2}$

Please cite this paper as: Roberts KE, Hardy-Fairbanks, AJ, Stockdale CK. The effects of obesity with pregnancy termination: a literature review. Proc Obstet Gynecol. 2014;4(2): Article 3 [ 5 p.]. Available from: http://ir.uiowa.edu/pog/. Free full text article.

Corresponding author: Abbey J. Hardy-Fairbanks, MD, University of lowa Hospitals and Clinics, Department of Obstetrics and Gynecology, 200 Hawkins Drive, lowa City, IA 52242. Telephone: 319-356-2291. abbey-hardyfairbanks@uiowa.edu.

Financial Disclosure: The authors report no conflict of interest.

Copyright: (c) 2014 Roberts et al. This is an open-access article distributed under the terms of the Creative Commons Attribution License, which permits unrestricted use, distribution, and reproduction in any medium, provided the original author and source are credited. 
It is estimated that one in two pregnancies in the United States are unintentional, and that one in five pregnancies will end in termination. A French national population based survey noted obese women are less likely to see a healthcare provider for contraception and more likely to report an unintended pregnancy. ${ }^{3}$ Furthermore, they noted the odds of reporting an unintended pregnancy or an abortion were four times higher among women under 30 years if obese compared to those of normal weight. ${ }^{3}$ The objective of this review was to evaluate and summarize existing literature addressing the implications of body mass index (BMI) on pregnancy termination.

\section{Methods}

Relevant articles were identified through PubMed, Cochrane Library, and MedlinePlus electronic databases searched and review of reference lists of the identified relevant published works. Six articles were identified from 19982012 and are included in this review.

\section{Results}

Dark et al. analyzed patient BMI and second trimester dilation and evacuation procedure outcomes on 163 women undergoing elective abortion at a single clinic. ${ }^{4}$ Women with a BMI greater than or equal to 30 were compared to women of a lesser BMI. Procedure length for obese women was $20 \%$ longer compared to non-obese women. Providers rated the procedures $40 \%$ more difficult for obese women. Providers also noted that procedure length and difficulty, blood loss, and number of complications increased as BMI increased. The authors suggested that abortion providers should be aware of the trends identified, and consider special instruments and/or alterations in surgical technique for procedures on women with increased BMI.

Marchiano et al. analyzed 363 women between 5 and 24 weeks gestation confirmed by ultrasound to determine potential factors related to increased risk of blood loss. ${ }^{5}$ Specific variables analyzed were maternal age, parity, smoking history, and body habitus. Patients were excluded for pregnancy demise, preterm premature rupture of membranes, and Potter's syndrome. While none of the factors significantly affected blood loss with dilation and curettage procedures in first trimester pregnancy terminations, simple and stepwise regression analyses suggested that BMI greater than or equal to 32.3 was the only variable significantly associated with increased blood loss in dilation and evacuation in second trimester pregnancy termination $(p<0.05)$.

Cosby et al. surveyed 43 abortion providers in the same healthcare system in an urban-hospital based clinic and found no statistically significant difference in how challenging surgical abortions were in women of normal BMI, overweight BMI, and obese $\mathrm{BMI}^{6}$ However, it is likely the study was underpowered to demonstrate a difference as a review of the provider's responses noted that $15 \%$ of the surveyed providers claimed surgical abortions were "not challenging" in obese women compared women with normal BMI, while $85 \%$ of providers ranged their responses from "somewhat challenging" to "extremely challenging". Specific challenges noted for obese 
women included visualizing the cervix, general anesthesia risks, and delays in care leading to increased gestational age.

Foster et al. performed a cross-sectional computer survey on 398 women presenting for second trimester elective abortion at a single urban hospital to evaluate the potential factors that cause a delay in abortion care. ${ }^{7}$ The investigators divided the abortion process into three specific steps: 1) discovering one was pregnant, 2) calling a clinic for an abortion appointment, and 3) receiving an abortion procedure. Obesity was associated with a delay in discovering one was pregnant [hazard ratio (HR) $0.8,95 \% \mathrm{Cl} 0.6-1.0]$. Other factors that were associated with such a delay were drug and alcohol abuse, prior second-trimester abortion, unknown last menstrual period, denial, and fear of procedure.

Murphy et al. performed a retrospective review including 1044 women undergoing second-trimester termination of pregnancy with ultrasound guidance between 13 0/7 and 24 0/7 weeks gestational age to compare perioperative risks in obese and nonobese women $(\mathrm{BMI}<30) .{ }^{8}$ While the complication rate was similar between groups $(5.5 \%$ nonobese and $7.6 \%$ obese), the operative times and anesthesia times were longer in obese patients (4.4 $\mathrm{min}$ and $5 \mathrm{~min}$ longer respectively, $\quad \mathrm{p}<0.001 \quad$ each). Additionally, history of one or more prior cesarean section was independently associated with major complication $(p=0.001)$ and gestational age above 18 weeks showed a nonsignificant trend toward more complications $(p=0.20)$. The authors suggested a potential for complications at advanced gestational age which was not statically confirmed. While this is the largest study evaluating obesity and second trimester termination of pregnancy identified for the review, the low complication rate decreased the power to detect a difference between groups.

Strafford et al. investigated outcomes of medical abortions in obese women compared to non-obese women. ${ }^{9}$ The authors performed a retrospective chart review of 1,398 medical abortions from January 1, 2005 through December 31, 2007. All abortion regimens consisted of mifepristone $200 \mathrm{mg}$ orally and misoprostol 800 micrograms vaginally or buccally within 24 hours. Women were excluded due to nonviable pregnancy, incomplete abortion, missing data, or an age younger than 18 years. Of the 1,398 charts reviewed, 1,202 women were eligible for study inclusion of which 861 women had a BMI of less than 30 , and 341 women had a BMI of greater than or equal to 30 . The outcome following medical abortion was similar among both groups of women. Specifically, there was no significant difference between obese and non-obese women in terms of need for uterine aspiration post initial abortion, completed abortion within two weeks of medication administration, number of additional clinic visits, additional doses of misoprostol, and loss to follow up. Additional comparisons were analyzed in stratified BMI categories with no statistically significant comparisons suggesting the rates of the studied outcomes are similar across all BMI categories. 


\section{Discussion}

Pregnancy termination on obese women may impart additional technical challenges. While experienced providers are able to complete procedures in obese women without statistically significant differences in procedure or patient outcomes compared to normal weight women for first trimester gestations, pharmacological abortion may be a more practical option in some very obese women. From the limited evidence available for review, providers should be aware that obesity was noted to have significant effects on later gestation (second trimester) abortion outcomes.

Available information regarding the risks of procedures should be presented to patients during counseling. It is imperative to note data regarding the effects of obesity with pregnancy termination is limited by the small number of studies, and methodologies. Due to the increasing obesity epidemic within this country and worldwide, further research should be conducted including BMI stratification with analysis between non-obese, obese, and morbidly obese women.

\section{References}

1. Finkelstein EA, Khavjou OA, Thompson H, Trogdon JG, Pan L, Sherry B, Dietz W. Obesity and severe obesity forecasts through 2030. Am J Prev Med. 2012 Jun;42(6):563-70. doi: 10.1016/j.amepre.2011.10.026. PubMed PMID: 22608371.
2. American College of Obstetricians and Gynecologists. ACOG Committee opinion no. 549: obesity in pregnancy. Obstet Gynecol. 2013 Jan;121(1):213-7. doi:

http://10.1097/01.AOG.0000425667.103 77.60. PubMed PMID: 23262963.

3. Bajos N, Wellings K, Laborde C, Moreau C; CSF Group. Sexuality and obesity, a gender perspective: results from French national random probability survey of sexual behaviours. BMJ. 2010 Jun 15;340:c2573. doi: 10.1136/bmj.c2573. PubMed PMID: 20551118.

4. Dark AC, Miller L, Kothenbeutel RL, Mandel L. Obesity and second-trimester abortion by dilation and evacuation. $\mathrm{J}$ Reprod Med. 2002 Mar;47(3):226-30. PubMed PMID: 11933688.

5. Marchiano DA, Thomas AG, Lapinski R, Balwan K, Patel J. Intraoperative blood loss and gestational age at pregnancy termination. Prim Care Update Ob Gyns. 1998 Jul 1;5(4):204-205. http://dx.doi.org/10.1016/S1068-

607X(98)00144-9. PubMed PMID: 10838389.

6. Cosby K, Weitz T, Foster, DG. Obesity and Abortion. Abstract originally presented at National Abortion Federation's Annual Meeting; April 23, 2007; Boston, Massachusetts. http://www.medscape.com/viewarticle/5 64707_6.

7. Foster DG, Jackson RA, Cosby K, Weitz TA, Darney PD, Drey EA. Predictors of delay in each step leading to an abortion. Contraception. 2008 Apr;77(4):289-93. doi: 10.1016/j.contraception.2007.10.010. Epub 2008 Feb 13. PubMed PMID:18342653. 
8. Strafford MA, Mottl-Santiago J, Savla A, Soodoo N, Borgatta L. Relationship of obesity to outcome of medical abortion. Am J Obstet Gynecol. 2009 May;200(5):e34-6. doi: 10.1016/j.ajog.2008.10.016. Epub 2008 Dec 25. PubMed PMID: 19110221.

9. Murphy LA, Thornburg LL, Glantz JC, Wasserman EC, Stanwood NL, Betstadt SJ. Complications of surgical termination of second-trimester pregnancy in obese versus nonobese women. Contraception. 2012 Oct;86(4):402-6. doi: 10.1016/j.contraception.2012.02.006. Epub 2012 Mar 23. PubMed PMID: 22445440. 